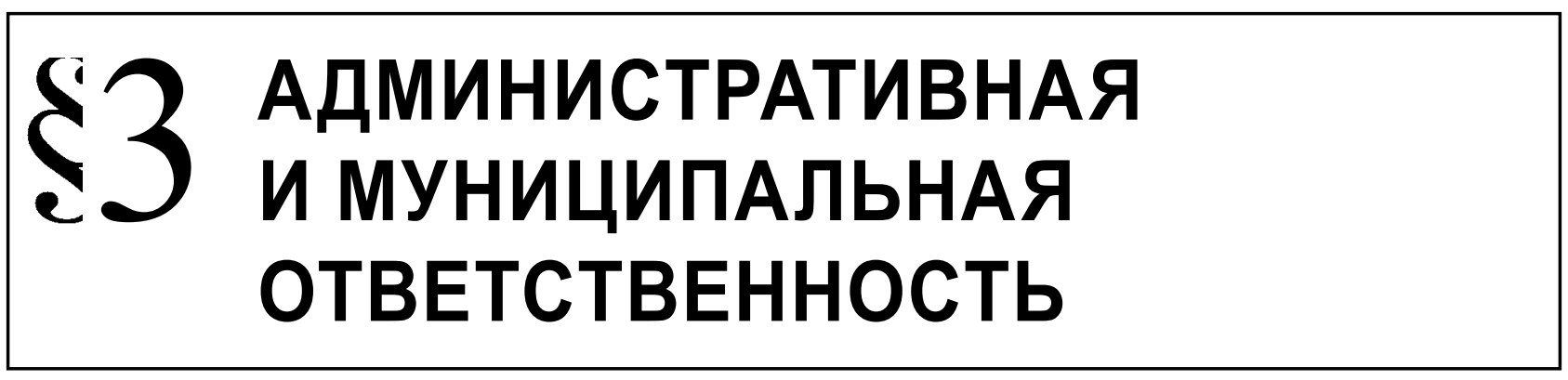

Сидоров Е.И.

\title{
ПРЕДМЕТ ДОКАЗЫВАНИЯ И ДОКАЗАТЕЛЬСТВА ПО ДЕЛАМ ОБ АДМИНИСТРАТИВНЫХ ПРАВОНАРУШЕНИЯХ В ОБЛАСТИ ТАМОЖЕННОГО ДЕЛА
}

Аннотация: Статья посвящена актуальным вопросам предмета доказывания и применения доказательств по делам об административных правонарушениях в области таможенного дела в условиях создания и функционирования Таможенного союза. Автор исследует правовые основы, понятие, виды и особенности доказательств, их роль в административно-юрисдикционном процессе таможенных органов, порядок процессуального оформления и пути совершенствования по их применению. В современных условиях всвязи с созданием и функционированием Таможенного союза в рамках ЕврАзЭС продолжается либерализация административного и таможенного законодательства. Однако наряду с этим одним из важнейших направлений деятельности таможенных органов России продолжает оставаться правоохранительная функция. Ее составной частью является борьба с административными правонарушениями в области таможенного дела. Необходимо отметить, что за исследуемый период количество нарушений таможенных правил, остается значительным и имеет тенденцию к росту. Методологическую основу диссертации составили современные достижения теории познания. В процессе исследования применялись общефилософский, теоретический, общефилософские методы (диалектика, системный метод, анализ, синтез, аналогия, дедукция, наблюдение, моделирование), традиционно правовые методы (формально-логический), а также методы, используемые в конкретно-социологических исследованиях (статистические, экспертные оценки и др.). Успешное решение задач производства по делам об административных правонарушениях в области таможенного дела, а именно: своевременное, полное и объективное выяснение обстоятельств каждого дела, разрешение его в точном соответствии с законодательством, обеспечение исполнения вынесенного постановления, а также выявление причин и условий, способствующих свершению административных правонарушений, предупреждение правонарушений, во многом предопределяется четким представлением о предмете данной деятельности - предмете доказывания и применением доказательств по данным делам.

Ключевые слова: таможня, Союз, правонарушение, ответственность, состав, наказание, регулирование, принцип, доказывание, доказательство.

$\mathrm{B}$ современных условиях всвязи с созданием и функционированием Таможенного союза в рамках ЕврАзЭС продолжается либерализация административного и таможенного законодательства. Однако наряду с этим одним из важнейших направлений деятельности таможенных органов России продолжает оставаться правоохранительная функция. Ее составной частью является борьба с административными правонаруше- ниями в области таможенного дела. Необходимо отметить, что за исследуемый период количество нарушений таможенных правил, остается значительным и имеет тенденцию к росту. Как показывает анализ практики ФТС России, за 2011 г. было возбуждено 72951 дел, в 2012 г. - 79 170, в 2013 г. 79727. Наибольшее количество дел возбуждается по так называемым «контрабандно» образующим составам, которые представляют наибольшую 
угрозу экономической безопасности России, например по статье 16.2 КоАП РФ «Недекларирование либо недостоверное декларирование товаров» в 2011 было возбуждено - 21957 дел или 30\% от общего количества дел, в 2012г - 21555 или 27\% от общего количества дел, за 2013 г. - 22593 или $28 \%$ от общего количества дел. Наряду с этим по статье 16.3 КоАП РФ «Несоблюдение запретов и (или) ограничений на ввоз товаров на таможенную территорию Таможенного союза или в Российскую Федерации и (или) вывоз товаров с таможенной территории Таможенного союза или из Российской Федерации» в 2011 г возбуждено в 2011 - 6727 дел или $9 \%$ от общего количества дел, в 2012 - 8960 или $11 \%$ от общего количества дел, в 2013 - 10602 или $13 \%$ от общего количества дел. ${ }^{1}$

Успешное решение задач производства по делам об административных правонарушениях в области таможенного дела, а именно: своевременное, полное и объективное выяснение обстоятельств каждого дела, разрешение его в точном соответствии с законодательством, обеспечение исполнения вынесенного постановления, а также выявление причин и условий, способствующих свершению административных правонарушений, предупреждение правонарушений, - во многом предопределяется четким представлением о предмете данной деятельности - предмете доказывания и применением доказательств по данным делам.

Под предметом доказывания понимается совокупность обстоятельств, подлежащих доказыванию по делу об административных правонарушениях. Перечень этих обстоятельств дан в главе 26 КоАП РФ. К ним относятся:

- событие правонарушения, то есть предусмотренное соответствующей статьей Таможенного кодекса Таможенного союза или Федерального закона «0 таможенном регулировании в Российской Федерации». - от 27 ноября 2010г. №311-Ф3 общественно опасное деяние со всеми характеризующими его обстоятельствами (время, место, способ и другие обстоятельства совершения нарушения таможенных правил).

- виновность физического лица или юридического лица в совершении нарушения таможенных правил. Необходимо установить, совершило ли лицо, привлекаемое к ответственности, вменяемое ему в вину деяние, фамилию этого лица, его имя, отчество, дату и место рожде-

\footnotetext{
1 Информационно-аналитический обзор правоохранительной деятельности таможенных органов (за 2011-2013 годы)
}

ния, национальность, образование и другие данные о нем, которые позволяют с несомненностью удостоверить его личность.

- факт совершения нарушения таможенных правил предприятием, учреждением или организацией, осуществляющим деятельность в сфере таможенного дела а также индивидуальным предпринимателем.

- обстоятельства, влияющие на степень и характер ответственности лица, привлекаемого к ответственности за нарушение таможенных правил.

- причины и условия, способствовавшие совершению нарушение таможенных правил. Зачастую они могут влиять на характер и степень ответственности, имеют существенное значение для правильного разрешения дела и подлежат доказыванию в обычном порядке. Их выявление необходимо также для проведения профилактических мероприятий и выработки мер борьбы с нарушением таможенных правил. Таким образом обстоятельства, подлежащие доказыванию, которые перечислены в статье 26.1 КоАП РФ, конкретизируются с учетом особенностей каждого дела о нарушении таможенных правил в зависимости от состава расследуемого правонарушения. Содержание предмета доказывания зависит также от особенностей отдельных категорий дел. В производстве по делам о нарушении таможенных правил субъектами доказывания являются таможенные органы и должностные лица.

Конкретизацией его содержания в каждом случае служат диспозиция статьи главы 16 КоАП России «Административные правонарушения в области таможенного дела»(Нарушение таможенных правил), по которой квалифицируется совершенное правонарушение. В настоящее время данная глава насчитывает 24 статьи и 44 состава и действует в редакции Федерального закона от 6 декабря 2009 года №409-Ф3. ${ }^{2}$

Наряду с этим в ряду случаев в процессе установления истины по делу о нарушении таможенных правил нередко определенную значимость для него приобретают различного рода факты географического, экономического и социально-политического характера, а также законов природы в жизни людей и т.д. Например, стихийные бедствия,

\footnotetext{
Кодекс Российской Федерации об административных правонарушениях от 30.12.2001. № 195-Ф3 // Собрание законодательства Российской Федерации. 2002. № 1 (часть I) Ст. 1 (с посл. изм. и доп.).
} 
чрезвычайные ситуации, военные действия и др. Подобного рода факты именуются «общеизвестными» и не нуждаются в доказывании. Следует отметить целью доказывания является установление истины по делу, вытекающей из совокупности собранных фактических данных, логического их осмысления, основанного на правильном толковании правовых норм, а содержанием доказывания является собирание, исследование, оценка доказательств, их использование при рассмотрении дела.

Резюмируя вышеизложенное автор отмечает предмет доказывания - это сердцевина, ядро или основа всех познаваемых по делу обстоятельств. Он включает в себя такие обстоятельства, которые непременно должны быть установлены посредством специальной процедуры административного доказывания путем применения имеющихся по делу доказательств.

В статье 26.2. КоАП РФ дано развернутое определение доказательств. Доказательствами по делу о нарушении таможенных правил являются любые фактические данные, на основании которых судья, орган, должностное лицо таможенного органа, в производстве которых находится дело, устанавливают наличие или отсутствие события административного правонарушения, виновность лица, привлекаемого к административной ответственности, а также иные обстоятельства, имеющие значение для правильного разрешения дела. Эти данные устанавливаются протоколами, объяснениями лица, привлекаемого к ответственности, показаний потерпевшего, свидетелей, заключениями эксперта, иными документами, а также показаниями специальных технических средств, вещественными доказательствами.

Следует отметить нормы главы 26 КоАП РФ в целом раскрывают общий порядок использования доказательств по делам об административных правонарушениях, поэтому автор акцентирует внимание на особенности применения доказательств по делам о нарушении таможенных правил.

Для рассматриваемого вида доказательства характерны два признака, относящиеся к способу их получения:

- они могут быть получены только в процессе производства по делу о нарушении таможенных правил путем совершения процессуального действия;

- фактические данные, содержащиеся в протоколе, должны быть закреплены в порядке, предусмотренном КоАП России, должностным лицом таможенного органа, уполномоченным на совершение процессуального действия.
Проверка и оценка протоколов и других документов, несмотря на то, что они происходят от должностных лиц таможенных органов, осуществляются на тех же основаниях, что и всех иных видов доказательств, так как они не имеют заранее установленной силы и не исключено, что в них могут содержаться искажения, ошибки, неточности.

К протоколам процессуальных действий предъявляются высокие требования в части строгого соблюдения процессуальных норм, определяющих порядок их производства и фиксации.

Протокол процессуального действия должен быть составлен только правомочным должностным лицом указанным в КоАП России. В целях реализации положений части 2 статьи 23.7 , части 4 статьи 28.3, части 1 статьи 28.6 КоАП РФ в таможенных органах перечень должностных лиц, уполномоченных составлять протоколы об административных правонарушениях и осуществлять производство, определен Приказом ФТС России от 01 марта 2012 г. № $368^{3}$. В основном - это сотрудники подразделений административных расследований и должностные лица таможенных постов.

Наряду с этим одной из главных особенностей использования доказательств по делам о нарушении таможенных правил является то, что ими так же могут быть результаты таможенного контроля. Так в соответствии со статьей 171 Федерального закона «0 таможенном регулировании в Российской Федерации» «результаты проведения таможенного контроля, оформленные в соответствии с положениями действующего законодательства, могут быть допущены в качестве доказательств по делам об административных правонарушениях и подлежат оценке судом, арбитражным судом или должностным лицом при рассмотрении указанных дел, жалоб на решение, действие (бездействие) таможенных органов и их должностных лиц либо дел по экономическим спорам, разрешаемым арбитражным судом, наряду с другими доказательствами в соответствии законодательством Российской Федерации об административных правонарушениях.»"

\footnotetext{
Приказ ФТС России от 01.03.2012 № 368 «О должностных лицах таможенных органов Российской Федерации, уполномоченных составлять протоколы об административных правонарушениях и осуществлять административное задержание» // Российская газета. - 2012 г. 20 апреля.

4 Федеральный закон «О таможенном регулировании в Российской Федерации». - от 27 ноября 2010г. №311-Ф3. - // СЗ РФ, 2010 №48, Ст. 6252.
} 
В настоящее время ими являются акты осмотра помещений и территорий для целей таможенного контроля, акты таможенного осмотра и досмотра товаров и транспортных средств, акты о проведении таможенной проверки, акты о применении технических средств таможенного контроля, (форма актов утверждена решением комиссии Таможенного союза, с 2012 года утверждается решением Евразийской экономической комиссии), справки, рапорта, докладные записки и пр.. Однако результаты таможенного контроля приобретают статус доказательств только после возбуждения дела о нарушении таможенных правил. Например в соответствии с пунктом 9 статьи 122 Таможенного кодекса Таможенного союза «при установлении в ходе таможенной проверки признаков административного правонарушения таможенными органами принимаются меры в соответствии с административным законодательством России». ${ }^{5}$

Не допускается использование доказательств по делу о нарушении таможенных правил, полученных с нарушением закона, в том числе и при проведении таможенного, валютного, транспортного и других видов государственного контроля, относящихся к компетенции таможенных органов.

По мнению автора в доказательстве, как в любом отражении, следует различать две главные его стороны - содержание и форму. Содержанием в доказательстве являются заключенные в нем сведения, то есть фактические данные, а формой, способом существования и выражения отображения - источник фактических данных. Так, например, содержанием показаний свидетеля будут сообщаемые на опросе свидетелем фактические данные, а формой - само сообщение, сделанное свидетелем на опросе и записанное в протоколе.

Доказательство можно определить как единство фактических данных (знаний о предмете доказывания или иных обстоятельствах, имеющих значение для дела) и законного источника фактических данных (устного, письменного или вещественного), полученного и процессуально оформленного в материалах дела в установленном законом порядке.

К доказательству предъявляются в соответствии с законом следующие основные требования:

\footnotetext{
Таможенный кодекс Таможенного союза от 27.11.2009 № 17. (Федеральный закон от 02 июня 2010 г. №114-Ф3 «О ратификации Договора о Таможенном кодексе Таможенного союза) // С3 РФ, 2010. №23. Ст. 2796.
}

a) содержащиеся в нем данные должны быть не просто «данными», но «фактическими данными», то есть являться не абстрактными оценочными суждениями или мнениями, а достаточно конкретными данными о вполне конкретных действиях людей, об определенных событиях и т.д., позволяя отвечать на вопросы, что, где, когда, каким образом случилось или произошло;

б) фактические данные должны быть относимыми к данному конкретному делу. Под относимостью доказательства понимается его способность подтверждать или опровергать определенное обстоятельство, подлежащее доказыванию по делу;

в) способы получения и формы закрепления доказательства должны соответствовать виду доказательства и источнику фактических данных. Соответствие доказательств требованиям закона к его процессуальной форме принято называть допустимостью доказательств.

Сущность всех указанных требований состоит в том, чтобы доказательства по делу о нарушении таможенных правил были собраны уполномоченными на то должностными лицами и эти лица действовали в пределах предоставленных им КоАП России полномочий, с соблюдением установленных им способов, порядка и форм.

В соответствии с законодательством должностное лицо таможенного органа, в производстве или на рассмотрении которого находится дело нарушении таможенных правил, оценивает доказательства по своему внутреннему убеждению, основанному на всестороннем, полном и объективном рассмотрении всех обстоятельств дела в их совокупности, руководствуясь законодательством Российской Федерации. Никакие доказательства не имеют заранее установленной силы (статья 26.11 КоАП РФ).

Оценка доказательств в совокупности предваряет собой готовность вынесения по делу постановления (решения). Однако оценке подлежит каждое отдельно взятое доказательство, относящееся к факту совершения нарушения таможенных правил.

В оценке нуждаются все добытые фактические данные. В основу вынесения постановления без доказывания (анализа) могут быть положены такие факты, достоверность которых не вызывает сомнения (например, сведения о совершенных ранее правонарушениях, содержащихся в официальных справках, базах данных).

Заключение эксперта, показания участников производства по делу о нарушении таможенных 
правил не могут быть положены в основу принятия решения, если они противоречат остальным доказательствам, материалам дела.

Оценка доказательств по внутреннему убеждению исключает вмешательство других органов и должностных лиц, их давление на процесс формирования и состояние убеждения тех лиц, которые компетентны принимать решения по существу по своему убеждению. Наряду с этим является весьма важным и необходимым элементом подготовки к вынесению решения по каждому конкретному делу. Умение всесторонне, полно и объективно оценивать доказательства оказывает влияние на законность принимаемых по делу решений.

В современных условиях на основе присущих им свойств доказательства о нарушении таможенных правил в теории принято делить на обвинительные и оправдательные, первоначальные и производные, прямые и косвенные.

Обвинительными являются доказательства, могущие служить для изобличения лица, привлекаемого к ответственности за нарушение таможенных правил, или установление обстоятельств, отягчающих его ответственность.

Оправдательными являются доказательства, могущие служить для установления невиновности физического лица или должностного лица, в отношении которого ведется производство по делу об административном правонарушении за нарушение таможенных правил, отсутствия нарушения таможенных правил со стороны юридического лица или обстоятельств, смягчающих их ответственность.

Первоначальными (или первичными) называют доказательства, полученные из первоисточника. Например, объяснения свидетеля - очевидца правонарушения, объяснения лица, в отношении которого ведется производство по делу за нарушение таможенных правил, о собственных неправомерных действиях.

Производными (или вторичными) называют доказательства, полученные не из первоисточника, а через посредствующее лицо, как бы из «вторых рук». Так, производными будут показания лиц в случаях, когда они сообщают не о лично воспринятых фактах, а со слов других лиц, являющихся их очевидцами. Производными также будут копии документов, содержащих сведения относительно обстоятельств, подлежащих доказыванию по делу.

Прямыми считают доказательства, которые своим содержанием однозначно подтверждают или опровергают существование любого из обстоятельств, подлежащих доказыванию по делу за нарушении таможенных правил.

Соответственно к косвенным относят доказательства, которые своим содержанием неоднозначно подтверждают или опровергают существование доказываемого обстоятельства по делу.

Прямое доказательство отражает доказываемое обстоятельство таким образом, что значение его содержания по отношению к последнему допускает единственное истолкование. Косвенное доказательство отражает существование подтверждаемого или опровергаемого им обстоятельства совершенно иначе. Значение его содержания по отношению к последнему допускает не одно, а несколько различных истолкований. Выбор единственного его истинного значения осуществляется методом исключения всех остальных значений обязательно путем опоры на совокупность других доказательств по делу.

Современные ученые, которые специализируются на исследовании «Теории доказательств в уголовном процессе» и характеризуют деление доказательств по видам источников, отмечают, что в его основу «положено различие процессуальных способов собирания и закрепления доказательств, соответствующих специфике отдельных видов фактических данных». Сказанное в полной мере относится и к доказательствам по делам о нарушении таможенных правил.

Следующей особенностью применения доказательств по делам о нарушении таможенных правил является эффективное использование результатов экспертизы, должностными лицами таможенных органов при производстве по данным делам. В настоящее время по делам о нарушении таможенных правил могут проводиться следующие виды экспертиз: товароведческая, криминалистическая, идентификационная, технологическая и др. В соответствии со статьей 26.4 КоАП России экспертиза назначается в случае, если для разъяснения возникающих вопросов требуются специальные познания в науке, искусстве, технике или ремесле.

Экспертиза проводится в основном экспертами таможенных лабораторий и других соответствующих учреждений либо иными специалистами, назначенными должностным лицом таможенного органа, в производстве или на рассмотрении которого находится дело о нарушении таможенных правил. В качестве эксперта может быть вызвано любое физическое лицо, обладающее необходи- 
мыми познаниями для дачи заключения. Определение о назначении экспертизы обязательно для эксперта, которому этим решением поручена экспертиза, и для должностных лиц предприятий, учреждений или организаций, где работает эксперт.

Заключение эксперта - это представленные по поручению должностного лица таможенного органа Российской Федерации в установленном законом порядке мотивированные выводы лица, обладающего специальными познаниями в науке, искусстве, технике или ремесле, об обстоятельствах, существенных для дела, полученные в результате их исследования с применением этих познаний.

Необходимость привлечения специальных познаний для выяснения обстоятельств дела о нарушении таможенных правил обусловлена разнообразием правонарушений, обстановкой их совершения, когда правильное установление фактов невозможно без обращения к содействию лиц, владеющих необходимыми специфическими знаниями и методами исследования.

Даже в тех случаях, когда должностное лицо таможенное органа обладает какими-либо специальными познаниями, необходимыми для выяснения тех или иных обстоятельств дела, закон не позволяет ему принимать на себя функции эксперта. Это обусловлено необходимостью квалифицированного, тщательного и объективного производства экспертизы с созданием необходимых гарантий для всесторонней критической проверки и оценки заключения эксперта как доказательства, опирающегося на специальные познания постороннего по отношению к делу лица.

Вопросы, поставленные перед экспертом, и его заключение не могут выходить за пределы специальных познаний эксперта.

Эксперт дает заключение в письменной форме от своего имени. В заключении эксперта излагаются проведенные им исследования, сделанные в результате их выводы и обоснованные ответы на поставленные вопросы. Если эксперт при производстве экспертизы установит имеющие значение для дела обстоятельства, по поводу которых ему не были поставлены вопросы, он вправе включить выводы об этих обстоятельствах в свое заключение.

Существенным недостатком нормативно-правового регулирования процесса экспертизы как доказательства по делам о нарушении таможенных правил являются отсутствие в законодательстве конкретных сроков ее проведения и оформления заключения, что значительно затрудняет производство по данным делам, в следствии чего нормы законодательства по данному вопросу требует оптимизации и корректировки.

Одной из особенностей по применению доказательств по делам о нарушении таможенных правил является специфические вещественные доказательства и документы. Вещественными доказательствами по делу об административном правонарушении служат:

- товары и транспортные средства, перемещаемые через таможенную границу Таможенного союза являвшиеся непосредственными объектами правонарушения;

- товары и транспортные средства со специально изготовленными тайниками, использованными для перемещения через таможенную границу Таможенного союза с сокрытием предметов, являющихся непосредственными объектами нарушения таможенных правил;

- документы и средства идентификации, использованные для незаконного перемещения товаров и транспортных средств через таможенную границу Таможенного союза;

- $\quad$ иные предметы, сохранившие на себе следы правонарушения либо могущие служить средством к обнаружению нарушения таможенных правил и выявлению лиц, совершивших правонарушение, а также к установлению фактических обстоятельств дела.

Сущность вещественного доказательства, в отличие от всех иных доказательств, содержащих словесное описание тем или иным лицом какоголибо факта, состоит в непосредственном материальном отображении, запечатлении фактических данных, на основании которых устанавливаются имеющие значение для дела доказательства.

Любое лицо, которое владеет предметом, обладающим признаками вещественного доказательства, обязано предъявить такой предмет должностным лицам таможенных органов.

Вещественные доказательства приобщаются к делу об административном правонарушении. Они должны быть подробно описаны в протоколах о нарушении таможенных правил, изъятия, или в иных протоколах. В случае необходимости вещественные доказательства могут быть сфотографированы или зафиксированы с помощью других технических средств и по возможности должны быть опечатаны.

Должностное лицо таможенного органа, в производстве или на рассмотрении которого находится дело об административном правонарушении, 
обязано принять все меры к обеспечению сохранности вещественных доказательств до окончательного разрешения дела.

Общий порядок и сроки хранения вещественных доказательств определены в статье 27.10 КоАП России. Здесь необходимо уточнить, что как позитивный момент следует отметить изъятые вещи (товары и транспортные средства) и документы до рассмотрения дела о нарушениях таможенных правил хранятся в местах, определяемых должностными лицами таможенных органов, процессуальное оформление и механизм реализации хранения изъятых вещей (товаров и транспортных средств) и документов нашли свое отражение в приказе ФТС России № 1339 от 18.12.2006 ${ }^{6}$. В соответствии с п. 21 данного приказа для хранения вещественных доказательств (не являющихся крупногабаритными) в таможенных органах выделяется отдельное помещение - камера хранения вещественных доказательств, однако наряду с этим в соответствии с п. 35 данного приказа, в случае невозможности хранения изъятых вещественных доказательств в таможенном органе они передаются на хранение организации, осуществляющей складские услуги в зоне деятельности таможенного органа (склад временного хранения).

Вещественные доказательства хранятся до истечения сроков обжалования постановления таможенного органа по делу об административном правонарушении или до принятия решения вышестоящим таможенным органом Российской Федерации или судом рассматривавшими жалобу на постановление таможенного органа по делу об административном правонарушении. Вещественные доказательства, которые в соответствии с постановлением таможенного органа по делу об административном правонарушении подлежат конфискации, конфискуются в порядке, предусмотренном Российским законодательством.

Необходимо констатировать, документы признаются доказательствами, если сведения, изложенные или удостоверенные в них физическими, юридическими лицами, индивидуальными предпринимателями осуществляющими деятельность в сфере таможенного дела, имеют значение для производства по делу о нарушении таможенных правил. Документы могут содержать сведения, за-

\footnotetext{
6 Приказ ФТС России от 18.12.2006 № 1339 «О порядке хранения, изъятых вещей и документов, имеющих значение доказательств по делам об административных правонарушениях» // Российская газета. 2007. 23 мая.
}

фиксированные как в письменной, электронной, так и в иной форме. К документам могут быть отнесены материалы фото- и киносъемки, звуко- и видеозаписи, информационных баз и банков данных и иные носители информации.

Должностными лицами таможенных органов могут изыматься документы (оригиналы) либо заверенные копии, к которым относятся: книжки МДП, инвойсы, счета-фактуры, упаковочные листы, ГТД с прилагаемым пакетом документов, товарно-транспортные накладные и другие документы. В случаях, если они обладают признаками, указанными в статье 26.6 КоАП России, такие документы являются вещественными доказательствами. Документы, являющиеся вещественными доказательствами, остаются в деле о нарушении таможенных правил в течение всего срока хранения этого дела либо передаются заинтересованным государственным учреждениям.

Еще одной особенностью применения доказательств по делам о нарушении таможенных правил, является новелла КоАП РФ, которая в определенной мере, ликвидировала правовой пробел, который касается понятия «техническое средство» и условий, при которых показания приборов будут являться доказательствами по делам о нарушении таможенных правил. В соответствии со ст. 26.2 КоАП РФ «доказательствами по делам о нарушении таможенных правил, могут быть и показания специальных технических средств». Сами же требования к приборам и правилам фиксации показаний прописаны в ст. 26.8 КоАП РФ «Показания специальных технических средств».

В соответствии с ч. 1. данной статьи «под специальными техническими средствами понимаются измерительные приборы, утвержденные в установленном порядке в качестве средств измерения, имеющие соответствующие сертификаты и прошедшие метрологическую проверку». В соответствии с ч. 2. данной статьи «показания специальных технических средств отражаются в протоколе об административном правонарушении», а в соответствии со статьей 107 Таможенного кодекса Таможенного союза «показания технических средств таможенного контроля оформляются актом». Однако введенный в КоАП РФ термин «специальное техническое средство» охватывает только те средства, показания которых могут использоваться в качестве доказательств. Вследствие этого, автор разделяет позицию некоторых ученых, которые предлагают к числу технических средств, используемых при таможенном контроле отнести: досмо- 
тровые фонари, досмотровые зеркала и т.п., которые не являются измерительными приборами.

В настоящее время должностными лицами таможенных органов при проведении таможенного контроля и досмотра транспортного средства как меры обеспечения производства (ст.27.9 КоАП РФ) могут применяться технические средства таможенного контроля, облегчающие осмотр, обнаружение и фиксацию доказательств. Наиболее активно используются следующие технические средства таможенного контроля:

- видеосистема «Взгляд» - предназначена для обнаружения контрабанды в труднодоступных местах (большегрузные автомобили, железнодорожные вагоны, а так же для проверки емкостей с водой, горюче-смазочными материалами и спиртосодержащими жидкостями);

- п полужесткий видеоскоп «Крот»- применяется для исследования бака автомобиля, полостей автомобиля, дверей автомобиля;

- радиотехнический аппарат «Зонд-М» - предназначен для обнаружения контрабанды в однородных грузах (песок, щебенка, глина и т.п.) перевозимых автомобильным и железнодорожным транспортом;

- инспекционно-досмотровой комплекс - предназначен для рентгеноскопического действия по обнаружению контрабанды в автомобилях, железнодорожных вагонах и другие.

В случае необходимости для фиксации процесса досмотра транспортного средства и обнаруженных при досмотре доказательств применяются фото и киносъемка, видеозапись и иные установленные способы фиксации вещественных доказательств (ч. 4 ст. 27.9 КоАП РФ).

Таким образом исходя из вышеизложенного в качестве вывода следует отметить: выявленные пробелы правового регулирования по применению доказательств по делам о нарушении таможенных правил учитывая специфику данных дел, а также происходящие изменения в таможенной политике и реалий складывающихся правоотношений в области таможенного дела, нуждаются в дальнейшем совершенствовании и корректировки.

С этой целью предлагается:

- $\quad$ дополнить статью 26.4 КоАП РФ «Экспертиза» нормой устанавливающей срок проведения экспертизы и оформление заключения эксперта;

- $\quad$ расширить понятие специальное техническое средство предусмотренное статьей 26.8 КоАП РФ включив в него технические средства не являющиеся измерительными приборами.

\section{Библиография:}

1. Кодекс Российской Федерации об административных правонарушениях от 30.12.2001. № 195-Ф3 // Собрание законодательства Российской Федерации. 2002. № 1 (часть I) Ст. 1 (с посл. изм. и доп.).

2. Россинский Б.В., Старилов Ю.Н.. Административное право: учебник для вузов, 4 изд. - М.: Норма: Инфра-М, 2010.

3. Хомяков Л.Л., Карпеченков М.Ю., Сидоров Е.И. Административное производство по делам о нарушении таможенных правил: курс лекций М.: Изд-во РТА, 2011 г.

4. Стригунова Н.Ю. Доказывание по делам об административных правонарушениях в области таможенного дела в государствах-членах Таможенного союза ЕврАзЭС (сравнительно-правовой анализ) // Административное и муниципальное право. - 2013. - 10. - C. 980 - 985. DOI: 10.7256/1999-2807.2013.10.9765.

5. Обыденов В.В. К вопросу о содержание обстоятельств, смягчающих административную ответственность и их соотношение с обстоятельствами связанными с освобождением от административной ответственности // Административное и муниципальное право. - 2013. - 10. - С. 965 - 975. DOI: 10.7256/1999-2807.2013.10.9717.

6. Куракин А.В. Компетенция полиции в сфере реализации законодательства об административных правонарушениях // NB: Административное право и практика администрирования. - 2013. - 4. - С. 28 - 48. DOI: 10.7256/23069945.2013.4.8841. URL: http://www.e-notabene.ru/al/article_8841.html

7. Обыденов В.В. Обстоятельства смягчающие административную ответственность в юрисдикционной деятельности полиции // Полицейская деятельность. - 2013. - 4. - С. 244 - 253. DOI: 10.7256/2222-1964.2013.4.9582.

8. Сидоров Е.И. Проблемы применения ареста товаров и транспортных средств как меры обеспечения производства по делам об административных правонарушениях в области таможенного дела // Административное и муниципальное право. - 2012. - 1. - С. $59-62$.

9. Костенников М.В., Куракин А.В. К вопросу об основании административной ответственности в российском праве // NB: Административное право и практика администрирования. - 2013. - 10. - С. 75 - 88. DOI: 10.7256/23069945.2013.10.10153. URL: http://www.e-notabene.ru/al/article_10153.html

10. Куракин А.В., Бадулин А.Д., Трегубова Е.В. Административная ответственность за правонарушения на рынке алкоголя и роль полиции в ее реализации // NB: Административное право и практика администрирования. - 2013. 10. - C. 28 - 74. DOI: 10.7256/2306-9945.2013.10.10151. URL: http://www.e-notabene.ru/al/article_10151.html 
11. Костенников М.В., Куракин А.В., Трегубова Е.В. Конституционное право на проведение мирных собраний, митингов, демонстраций, шествий и пикетирования и административная ответственность как средство его обеспечения // NB: Административное право и практика администрирования. - 2013. - 8. - С. 82 - 105. DOI: 10.7256/23069945.2013.8.9955. URL: http://www.e-notabene.ru/al/article_9955.html

\section{References (transliterated):}

1. Kodeks Rossiiskoi Federatsii ob administrativnykh pravonarusheniyakh ot 30.12.2001. № 195-FZ // Sobranie zakonodatel'stva Rossiiskoi Federatsii. 2002. № 1 (chast' I) St. 1 (s posl. izm. i dop.).

2. Rossinskii B.V., Starilov Yu.N.. Administrativnoe pravo: uchebnik dlya vuzov, 4 izd. - M.: Norma: Infra-M, 2010.

3. Khomyakov L.L., Karpechenkov M.Yu., Sidorov E.I. Administrativnoe proizvodstvo po delam o narushenii tamozhennykh pravil: kurs lektsii M.: Izd-vo RTA, $2011 \mathrm{~g}$.

4. Strigunova N.Yu. Dokazyvanie po delam ob administrativnykh pravonarusheniyakh $\mathrm{v}$ oblasti tamozhennogo dela v gosudarstvakh-chlenakh Tamozhennogo soyuza EvrAzES (sravnitel'no-pravovoi analiz) // Administrativnoe i munitsipal'noe pravo. - 2013. - 10. - S. 980 - 985. DOI: 10.7256/1999-2807.2013.10.9765.

5. Obydenov V.V. K voprosu o soderzhanie obstoyatel'stv, smyagchayushchikh administrativnuyu otvetstvennost' i ikh sootnoshenie s obstoyatel'stvami svyazannymi s osvobozhdeniem ot administrativnoi otvetstvennosti // Administrativnoe i munitsipal'noe pravo. - 2013. - 10. - S. 965 - 975. DOI: 10.7256/1999-2807.2013.10.9717.

6. Kurakin A.V. Kompetentsiya politsii v sfere realizatsii zakonodatel'stva ob administrativnykh pravonarusheniyakh // NB: Administrativnoe pravo i praktika administrirovaniya. - 2013. - 4. - S. 28 - 48. DOI: 10.7256/2306-9945.2013.4.8841. URL: http://www.e-notabene.ru/al/article_8841.html

7. Obydenov V.V. Obstoyatel'stva smyagchayushchie administrativnuyu otvetstvennost' v yurisdiktsionnoi deyatel'nosti politsii // Politseiskaya deyatel'nost'. - 2013. - 4. - S. 244 - 253. DOI: 10.7256/2222-1964.2013.4.9582.

8. Sidorov E.I. Problemy primeneniya aresta tovarov i transportnykh sredstv kak mery obespecheniya proizvodstva po delam ob administrativnykh pravonarusheniyakh v oblasti tamozhennogo dela // Administrativnoe i munitsipal'noe pravo. - 2012. - 1. - S. $59-62$.

9. Kostennikov M.V., Kurakin A.V. K voprosu ob osnovanii administrativnoi otvetstvennosti v rossiiskom prave // NB: Administrativnoe pravo i praktika administrirovaniya. - 2013. - 10. - S. 75 - 88. DOI: 10.7256/2306-9945.2013.10.10153. URL: http://www.e-notabene.ru/al/article_10153.html

10. Kurakin A.V., Badulin A.D., Tregubova E.V. Administrativnaya otvetstvennost' za pravonarusheniya na rynke alkogolya i rol' politsii v ee realizatsii // NB: Administrativnoe pravo i praktika administrirovaniya. - 2013. - 10. - S. 28 - 74. DOI: 10.7256/2306-9945.2013.10.10151. URL: http://www.e-notabene.ru/al/article_10151.html

11. Kostennikov M.V., Kurakin A.V., Tregubova E.V. Konstitutsionnoe pravo na provedenie mirnykh sobranii, mitingov, demonstratsii, shestvii i piketirovaniya i administrativnaya otvetstvennost' kak sredstvo ego obespecheniya // NB: Administrativnoe pravo i praktika administrirovaniya. - 2013. - 8. - S. 82 - 105. DOI: 10.7256/2306-9945.2013.8.9955. URL: http://www.e-notabene.ru/al/article_9955.html 